TITLE:

\title{
Endophytic fungi associated with leaves of Betulaceae in Japan.
}

$\operatorname{AUTHOR}(\mathrm{S})$ :

Osono, Takashi; Masuya, Hayato

\section{CITATION:}

Osono, Takashi ...[et al]. Endophytic fungi associated with leaves of Betulaceae in Japan.. Canadian journal of microbiology 2012, 58(4): 507-515

ISSUE DATE:

2012-04

URL:

http://hdl.handle.net/2433/155083

\section{RIGHT:}

(c) Copyright 2012 - Canadian Science Publishing.; この論文は出版社版 でありません。引用の際には出版社版をご確認ご利用ください。; This is not the published version. Please cite only the published version. 
1 Endophytic fungi associated with leaves of Betulaceae in Japan

2

3 Takashi Osono · Hayato Masuya

4

5 T. Osono. ${ }^{1}$ Center for Ecological Research, Kyoto University, Otsu, Shiga 520-2113 Japan

6 H. Masuya. Forestry \& Forest Products Research Institute, Tsukuba, Ibaraki 305-8687

7 Japan.

$8 \quad{ }^{1}$ Correspondence author (e-mail: tosono@ecology.kyoto-u.ac.jp).

9

10 Abstract: Diversity and species composition of endophytic fungi on leaves of 11 tree

11 species in Betulaceae were studied, with reference to climatic, tree species, and seasonal

12 variations. A total of 186 fungal isolates were obtained from 190 leaves collected in a

13 subalpine, a cool temperate, and a subtropical forest in Japan and were divided into 46

14 operational taxonomic units (OTUs) according to the base sequences of D1/D2 region of

15 LSU rDNA. The two most frequent OTUs were Muscodor sp. and Nemania sp. in

16 Xylariaceae, followed by Gnomonia sp., Glomerella acutata, Apiosporopsis sp., Asteroma

17 sp., and Cladosporium cladosporioides. The similarities of OTU composition in endophytic 
1 fungal assemblages on leaves of Betulaceae were generally low among the forests of

2 different climatic regions. Fungal OTU compositions were relatively similar between two

3 Betula species in subalpine forest, whereas seven tree species in cool temperate forest were

4 divided into three groups according to the similarity of endophytic fungal assemblages on

5 the leaves, with four Carpinus species assigned into two of the three groups. The similarity

6 of endophytic fungal assemblages between August and October was relatively high in

7 subalpine forest, whereas the seasonal changes were generally greater (i.e. the similarities

8 among sampling dates were lower) in cool temperate forest.

9 Key words: Betulaceae, climatic region, endophyte, seasonal change, tree leaves.

11 Introduction

Endophytic fungi include those that live within plant tissues at some time in their

14 life without causing apparent harm to their host (Saikkonen 2007; Sieber 2007). Endophytic

15 fungi on leaves of Betulaceae have been studied mainly in Europe and north America, with

16 emphasis on species richness (Sieber et al. 1991; Barengo et al. 2000; Green 2004), genetic

17 diversity (Lappalainen and Yli-Mattila 1999), relationships with genetic variations of host 
1 trees (Elamo et al. 1999; Ahlholm et al. 2002b; Saikkonen et al. 2003), interactions with

2 herbivores (Lappalainen and Helander 1997; Lappalainen et al. 1999; Ahlholm et al. 2002a;

3 Valkama et al. 2005), and effects of simulated acid rain (Helander and Rantio-Lehtimäki

4 1990; Helander et al. 1993a, 1993b). In contrast, basic information is still lacking on the

5 diversity and ecology of endophytic fungi of Betulaceous trees in Japan and Asian region,

6 despite their occurrence as major components of various forest types including alpine,

7 boreal, subalpine, temperate, and subtropical forests. Previous studies in Japan have

8 examined leaves of a total of 182 tree species in 54 families and detected 24 fungal genera

9 as endophytes (summarized in Osono 2009). Trees of Betulaceae have not been explored so

10 far regarding foliar fungal endophytes and are expected to host further array of fungal

11 diversity and functioning.

The purpose of the present study was to investigate the diversity and species composition of endophytic fungi on leaves of 11 tree species in Betulaceae, with reference

14 to climatic, tree species, and seasonal variations. Endophytic fungi were isolated from

15 healthy-looking leaves collected in a subalpine, a cool temperate, and a subtropical forest in

16 Japan by means of a surface disinfection method and used for molecular phylogenetic

17 analysis to determine putative taxa according to base sequences of D1/D2 region of LSU 
1 rDNA and to classify them into operational taxonomic units.

2

$3 \quad$ Materials and methods

4

$5 \quad$ Study site

6

Leaves of Betulaceous trees were collected at three study sites located in different

7 climatic regions in Japan: a subalpine, a cool temperate, and a subtropical forest. The

8 subalpine forest is located on Mt. Ontake, Gifu, central Japan $\left(35^{\circ} 56^{\prime} \mathrm{N}, 137^{\circ} 28^{\prime} \mathrm{E}\right.$, altitude

$92050 \mathrm{~m})$. The cool temperate forest is located in Ashiu Experimental Forest of Kyoto

10 University, Kyoto, central Japan $\left(35^{\circ} 18^{\prime} \mathrm{N}, 135^{\circ} 43^{\prime} \mathrm{E}\right.$, altitude $\left.660 \mathrm{~m}\right)$. The subtropical forest

11 is located in Yona Experimental Forest of University of the Ryukyus in the northern part of

12 Okinawa Island, Okinawa, south-western Japan $\left(26^{\circ} 9^{\prime} \mathrm{N}, 128^{\circ} 5^{\prime} \mathrm{E}\right.$, altitude $\left.250 \mathrm{~m}\right)$. Mean

13 annual temperature of the study sites is approximately $2^{\circ} \mathrm{C}, 10^{\circ} \mathrm{C}$, and $22^{\circ} \mathrm{C}$ in subalpine,

14 cool temperate, and subtropical forest, respectively, and annual precipitation is $2500 \mathrm{~mm}$,

$152353 \mathrm{~mm}$, and $2456 \mathrm{~mm}$, respectively. Details of the three study sites are described in

16 previous papers of litter-decomposing microfungi by the first author (Osono 2002; Osono

17 and Takeda 2007; Osono et al. 2008). Snow covers the forest floor from November to May 
1 in subalpine and from December to April in cool temperate forest, whereas no snow cover

2 has been observed in subtropical forest.

3

4 Sample collection

Leaves of a total of 11 deciduous tree species in four genera of Betulaceae were

collected in the present study, three species in the subalpine forest, seven in the cool

7 temperate forest, and one in the subtropical forest (Table 1). The 11 tree species are major

8 components of natural forest stands in the respective study sites. The collection was

9 performed during the growing season from May to November in 2008, once or three times

10 per tree species, according to Table 1. On each sampling occasion, a total of 10

11 healthy-looking leaves were harvested for each tree species from two arbitrarily chosen

12 trees growing naturally in forests, two branches per individual tree, at an approximate

13 height of 3-4 m. This made the harvest of a total of 190 leaves during the study period. The

14 leaves were placed in paper bags and taken to the laboratory.

One leaf disk was punched out from the central part of each sample leaf, avoiding

16 the primary vein, with a sterile cork borer $(5.5 \mathrm{~mm}$ in diameter). A total of 10 leaf disks

17 were used to isolate endophytic fungi for each tree species and on each sampling occasion. 
1 Fungi were isolated within $24 \mathrm{~h}$ of collection in the cool temperate forests and within $48 \mathrm{~h}$

2 in the subalpine and subtropical forest.

3

4 Fungal isolation

A surface disinfection method (Kinkel and Andrews 1988) was used to isolate endophytic fungi. The leaf disks were submerged in $70 \%$ ethanol (v/v) for 1 min to wet the

7 surface, then surface disinfected for $30 \mathrm{~s}$ in a solution of $15 \%$ hydrogen peroxide, and then

8 submerged again for $1 \mathrm{~min}$ in $70 \%$ ethanol. The disks were rinsed with sterile, distilled water, transferred to sterile filter paper in Petri dishes $(9 \mathrm{~cm}$ in diameter), and dried for $24 \mathrm{~h}$ to suppress vigorous bacterial growth after plating (Widden and Parkinson 1973). The disks

11 were placed on $9 \mathrm{~cm}$ Petri dishes containing lignocellulose agar (LCA) modified by Miura and Kudo (1970), two disks per plate. LCA contains glucose $0.1 \%, \mathrm{KH}_{2} \mathrm{PO}_{4} 0.1 \%$,

$13 \mathrm{MgSO}_{4} \cdot 7 \mathrm{H}_{2} \mathrm{O} 0.02 \%, \mathrm{KCl} 0.02 \%, \mathrm{NaNO}_{3} 0.2 \%$, yeast extract $0.02 \%$, and agar $1.3 \%$ (w/v).

14 Note that LCA modified by Miura and Kudo (1970) does not contain lignin or other

15 recalcitrant compounds. The modified LCA was used because its low glucose content

16 suppresses the overgrowth of fast-growing fungal species (Osono and Takeda 1999). Plates

17 were incubated at $20^{\circ} \mathrm{C}$ in the dark and observed at 1,4 , and 8 weeks after surface 
1 disinfection. Any hyphae or spores on the plates were subcultured on fresh LCA to establish

2 pure cultures.

3

4 Determination of OTUs

Obtained pure cultures were identified by morphology and molecular analysis.

Where fungal structures such as spores and sporocarps were produced on the medium, their

morphological characteristics were observed by using Nikon Optiphot microscope (Nikon

Inc. Tokyo). However, on many cultures, the fungal structures have not been seen. Thus,

identification of the cultures also was attempted by molecular analysis. Small amount of

mycelial tips from each culture were picked, crushed in the $24 \mu 1$ distilled water in the tube,

11 and microwaved at 12 seconds. They were used as templates for PCR. Fifty $\mu$ l of reaction

mixture containing $25 \mu$ Q Qiagen GoTaq premix and 10 pmol of each primer and distilled

water were added to the templates. The oligonucleotide primer-pair, NL1 and NL4 (White et

14 al. 1990) were used for PCR of ribosomal DNA large subunit D1/D2 region. The reactions

15 were initiated with 4 min of denaturation at $95^{\circ} \mathrm{C}$, followed by 40 cycles of two-step PCR,

16 consisting of $20 \mathrm{~s}$ at $94^{\circ} \mathrm{C}$ and $60 \mathrm{~s}$ at $56^{\circ} \mathrm{C}$ with final extension for $10 \mathrm{~min}$ at $72^{\circ} \mathrm{C}$ on a

17 GeneAmp 9700 thermal cycler (Perkin-Elmer Applied Biosystems, Foster City, California). 
1 Amplification products were purified by QIAquick PCR Purification Kit (QIAGEN), and

2 used for sequencing with a Big Dye Terminator Cycle Sequencing FS Ready Reaction kit

3 ver. 3.1 and ABI PRISM 3100 genetic analyzer (Perkin-Elmer Applied Biosystems). Both

4 strands of a fragment were sequenced. Sequence data sets were manually truncated both

5 ends and edited using the program BioEdit sequence editor version 5.09 (Hall 1999).

6 Homology searches were performed using each obtained sequences data on a BLAST

7 program at the National Center for Biotechnology Information (NCBI). Neighbor joining

8 trees were also constructed using MEGA version 5 (Tamura et al. 2011) with related

9 sequences from NCBI database. Isolates with more than $99 \%$ homology of sequence and

10 within the same cluster were treated as OTUs (operational taxonomy units) with tentative

11 codes for data analysis. In the case that obtained sequences contained polymorphic sites,

12 they are treated as the same OTUs with close relatives.

\section{Data analysis}

Frequency of occurrence of a single fungal OTU was calculated as the percentage of the number of disks containing the fungal OTU out of the 10 disks tested for each tree species on each sampling occasion. Fungal OTUs were regarded arbitrarily as major ones 
1 when equal to or more than five isolates were obtained during the investigation.

2

The degree of similarity of OTU composition among endophytic fungal

3 assemblages at different sites, tree species, and seasons was examined using Pianka's $\alpha$

4 (Pianka 1973), which is expressed by the following formula:

$$
\alpha_{1,2}=\sum_{i=1}^{\mathrm{S}} p_{1 i} p_{2 i} / \sqrt{\sum_{i=1}^{\mathrm{S}} p_{1 i}{ }^{2} \sum_{i=1}^{\mathrm{S}} p_{2 i}{ }^{2}}
$$

5 where $\alpha_{1,2}$ represents the similarity between assemblages 1 and $2, P_{1 i}$ and $P_{2 i}$ are the

6 proportions of the $i$ th species in assemblages 1 and 2, respectively, and $\mathrm{S}$ is the total number

7 of species. For $\alpha=1$, the two assemblages are identical in terms of their OTU composition. Principal component analysis was used to ordinate endophytic fungal assemblages

9 on leaves of Betulaceae, using data for 11 major fungal OTUs, with JMP ver. 6.0 software

10 (SAS Institute 2005). The data of B. ermanii in June and A. firma, B. grossa, and C.

11 laxiflora in May were not included in the analysis because of the low number of fungal

12 isolates obtained from these samples.

\section{Results}


species of Betulaceae each sampling occasion, making a total of 186 isolates from 190 leaves (Table 1). The 186 isolates were divided into 46 OTUs according to their base sequences of D1/D2 region of LSU rDNA (Table 2), with 0 to 13 OTUs being recorded per

5 tree species per sampling occasion (Table 1). Twenty-one $(46 \%)$ of the 46 OTUs were

6 singletons (Table 2). No endophytic fungi were isolated from Betula ermanii in June (Table

7 1). Most of the OTUs had sequences similar to those registered in GenBank database with

8 the similarity score of $95-99 \%$ and were identified to genus or species (Table 2). The two

9 most frequent OTUs were Muscodor sp. 11Bg52 and Nemania sp. 8Cs51 in Xylariaceae,

10 followed by Gnominia sp. 11Af11, Glomerella acutata, Apiosporopsis sp. 11Af21,

11 Asteroma sp. 8Ah91, and Cladosporium cladosporioides (Table 2).

Frequency of occurrence of major OUT Muscodor sp. 11Bg52 occurred on seven tree species in subalpine and cool temperate forests and was frequent on Alnus firma, Carpinus tschonoskii, and C. japonica in cool temperate forest in August (Table 3). Nemania sp. 8Cs51 occurred on seven tree species in subalpine, cool temperate, and subtropical forests and tended to be more frequent 
1 on warmer regions (Table 3). Gnomonia sp. 11Af11 occurred on B. ermanii and B.

2 platyphylla var. japonica in subalpine forest (Table 3). Glomerella acutata occurred on five

3 tree species in subalpine and cool temperate forests and was frequent on B. grossa and $C$.

4 cordata in cool temperate forest in August (Table 3). Apiosporopsis sp. 11Af21 occurred on

5 four tree species in cool temperate forest and was frequent on A. firma in November (Table

6 3). Asteroma sp. $8 \mathrm{Ah} 91$ occurred on three tree species in subalpine forest. Cladosporium

7 cladosporioides occurred on six tree species in cool temperate (in August) and subtropical

8 forests (in July). Khuskia sp. 11Bg11 and Nigrospora sp. 11Bg31 occurred on B. grossa and

9 C. laxiflora in November. Mycosphaerella sp. 8Ah31 occurred on A. hirsuta var. sibirica in

10 August. Pestalotiopsis sp. 8Ch61 occurred on C. sieboldiana in August.

Similarity among climatic regions

Similarity of endophytic fungal assemblages among climatic regions was

14 examined for leaves of the same tree genera collected on relatively close dates (Table 4).

15 The comparison of endophytic fungal assemblages on Alnus leaves in July to August gave

16 relatively low Pianka's similarity indices of 0.03 to 0.30 for three forest types, with the

17 greatest difference between subalpine and cool temperate forests (Table 4). This difference 
1 was consistent with the results of comparison on Betula leaves collected in August or in

2 October to November between subalpine and cool temperate forests, giving the similarity

3 indices of 0.00 to 0.07 (Table 4). Thus, the similarities of OTU composition in endophytic

4 fungal assemblages on leaves of Betulaceae were generally low among forest types in

5 different climatic regions.

6

$7 \quad$ Similarity among tree species

In subalpine forest in August, the similarity between two Betula species was much

higher than those between A. hirsuta var. sibirica and two Betula species (Table 5). In

11 not necessarily the case in cool temperate forest in August, in which seven tree species were

12 classified into three groups (Groups 1, 2, and 3) according to the similarity of OTU

13 composition of endophytic fungal assemblages (Table 5). Group 1 included A. firma, $C$.

14 japonica, and C. tschonoskii with Pianka's similarity indices of 0.68 to 0.82 (Table 5).

15 Muscodor sp. 11Bg52 was the most frequent OTU on the leaves of three tree species in

16 Group 1 (Table 3). Group 2 included B. grossa, C. laxiflora, and C. cordata with Pianka's

17 similarity indices of 0.65 to 0.84 (Table 5). Glomerella acutata was the most frequent OTU 
1 on the leaves of three tree species in Group 2 (Table 3). The similarities of endophytic

2 fungal assemblages between leaves of Groups 1 and 2 were relatively low ( 0.00 to 0.35$)$

3 (Table 5). Group 3 included Corylus sieboldiana. Pestalotiopsis sp. 8Ch61 was the most

4 frequent OTU on C. sieboldiana leaves, followed by G. acutata (Table 3). Endophytic

5 fungal assemblages of this tree species had the similarity indices of 0.00 to 0.05 to Group1

6 and 0.39 to 0.46 to Group 2 (Table 5). The similarity indices in cool temperate forest in

7 November were consistent with the results in August, with the higher similarity between $B$.

8 grossa and C. laxiflora in Group 2 than those between A. firma in Group 1 and two Group 2

9 tree species (Table 5).

11 Similarity among seasons

13 August and October for B. ermanii leaves in subalpine forest (Table 6). In contrast, the

14 similarity among seasons was generally low in cool temperate forest, with Pianka's

15 similarity indices between 0.00 and 0.19 (Table 6). 
3 accounted for $23.5 \%$ of total variance and characterized endophytic fungal assemblages on

4 leaves of Groups 2 and 3 in cool temperate forest in August (Fig. 1). PC2 (eigenvalue of

52.53 ) accounted for $23.0 \%$ of total variance and separated endophytic fungal assemblages in

6 cool temperate and subtropical forests from those in subalpine forest (Fig. 1). Component

7 loading of the major OTUs indicated that PC1 was positively associated with Cladosporium

8 cladosporioides, Glomerella acutata, and Pestalotiopsis sp. 8Ch61 and negatively with

$9 \quad$ Asteroma sp. 8Ah91, Khuskia sp. 11Bg11, Nigrospora sp. 11Bg31, Mycosphaerella sp.

10 8Ah31, and Gnomonia sp. 11Af11 (Fig. 1). PC2 was positively associated with Nigrospora

11 sp. 11Bg31, Khuskia sp. 11Bg11, Nemania sp. 8Cs51, and Muscodor sp. 11Bg52 and negatively with Asteroma sp. 8Ah91, Gnomonia sp., 11Af11 and Mycosphaerella sp. 8Ah31

(Fig. 1).

\section{Discussion}


1 leaves of trees in Ericaceae, Fagaceae, and pines (summarized in Osono 2009). Application

2 of a molecular phylogenic analysis to fungal isolates from leaves of 11 trees in Betulaceae

3 provides insights into putative taxonomy of fungal isolates including sterile mycelia, host

4 relationship, and seasonal changes of fungal OTUs from different climatic regions. and Nemania sp. 8Cs51, Table 2) on leaves of Betulaceae is consistent with previous studies

7 of endophytic fungi in other tree leaves in Japan (Okane et al. 1997; Osono 2002, 2008;

8 Osono and Mori 2004; Osono et al. 2008). Recent studies have demonstrated that

9 endophytic species of Muscodor produce volatile organic compounds with antimicrobial

10 and insecticidal activities (Daisy et al. 2002; Ezra et al. 2004; Lacey and Neven 2006).

11 Gnomonia and Glomerella (Table 2), as anamorphic Discula and Colletotrichum,

12 respectively, are known as pathogens and are also common components of foliar

13 endophytes (Okane et al. 1998; Sahashi et al. 2000; Hata et al. 2002; Osono and Mori 2005;

14 Osono 2008). Saikkonen et al. (2003) recorded Fusicladium betulae (an anamorph of

15 Ventulia ditricha) and Gnomonia setacea as foliar endophytes of young trees of Betula

16 ermanii and B. platyphylla planted in an experimental field in Finland. In the present study,

17 Gnomonia sp. 11Af11 and Ventulia sp. 8Be61, closely related to G. setaea and V. tremulae 
1 var. tremulae, respectively, were isolated from the same host trees in subalpine forest (Table

2 2). Cladosporium and Khuskia (including its anamorph Nigrospora) (Table 2) are known

3 well as primary saprobes on tree leaves (Hudson 1968; Osono et al. 2009).

By compared endophytic fungal assemblages on leaves of phylogenetically

5 diverse plant species collected from different climatic regions, Arnold and Lutzoni (2007)

6 found that the endophyte diversity decreased linearly from the tropics to northern boreal

7 forest. In the present study, such a climatic gradient was not found in the number of OTU of

8 endophytic fungi on leaves of Betulaceae from subalpine, temperate, and subtropical forests,

9 because of considerable variations between tree species within each forest type (Table 1).

10 By contrast, the similarity of fungal OTU composition among the climatic regions was

11 generally low (Table 4), which is consistent with Arnold and Lutzoni (2007) reporting that

12 the similarities of fungal species composition were generally low between the climatic

13 regions. It should be noted, however, that the differences in OTU composition between the

14 climatic regions in the present study were attributable to not only climatic factors but also

15 factors related to difference in plant species of the same genus (i.e., Table 5). Further studies

16 are thus needed to evaluate the relative importance of climatic condition and host plant on endophytic fungal assemblages. 
endophytic fungal assemblages in the cool temperate forest similar to the groups 1,2 , and 3

3 demonstrated in the present study. That is, Osono and Mori (2003) reported the frequent

4 occurrence of Xylariaceous endophytes on Fagus crenata leaves, whereas Osono and Mori

5 (2004, 2005) reported the frequent occurrence of Colletotrichum (an anamorph of

6 Glomerella) on Swida controversa leaves. Osono (2012) also showed that 73 deciduous tree

7 species in the study site were arranged along a continuum with these two types of foliar

8 fungal assemblages at the ends. Reasons for the continuity of the endophytic fungus-tree

9 leaf relationship remain unclear but would possibly be related to physical and chemical

10 properties of leaves, microenvironmental conditions of phyllosphere, and patterns of leaf

11 phenology.

13 showed relatively minor seasonal changes (Pianka's similarity index $=0.82$ ), compared to

14 those in cool temperate forest (0.00 to 0.19) (Table 6). Seasonal changes were also reported

15 for endophytic fungi on leaves of Swida controversa studied in the same cool temperate

16 forest (Osono and Mori 2005). The lower mean temperature and the lower variation in air

17 temperature during the growing season of subalpine forest (Osono and Takeda 2007) may 
1 partly account for the relatively minor changes in fungal OTU composition, compared to

2 those in cool temperate forest. Seasonal dynamics of endophytic fungi in subtropical forest

3 deserve future studies in this respect, as the mean temperature is higher but the seasonal

4 variation in temperature was relatively lower than in temperate regions.

5

6 Acknowledgments

We thank Mr. Osamu Tateno and members of Ashiu Experimental Forest of Kyoto

8 University for help with fieldwork; Dr. Norio Sahashi, Dr. Kunihiko Hata, and Dr. Izumi

9 Okane for useful discussions; and Dr. Elizabeth Nakajima for her critical reading of the

10 manuscript. This work was supported by the Global Environmental Research Fund

11 (RF-086) of the Ministry of the Environment, Japan and by the Global COE Program A06

of Kyoto University.

\section{References}

15 Ahlholm, J., Helander, M., Elamo, P., Saloniemi, I., Neuvonen, S., Hanhimäki, S., and 
2 Ahlholm, J., Helander, M., Henriksson, J., Metzler, M., and Sakkonen, K. $2002 \mathrm{~b}$. Environmental conditions and host genotype direct genetic diversity of Venturia ditricha, a fungal endophyte of birch trees. Evolution 56: 1566-1573.

5 Arnold, A.E., and Lutzoni, F. 2007. Diversity and host range of foliar fungal endophytes: are tropical leaves biodiversity hotspots? Ecology 88: 541-549.

Barengo, N., Sieber, T.N., and Holdenrieder, O. 2000. Diversity of endophytic mycobiota in leaves and twigs of pubsecent birch (Betula pubescens). Sydowia 52: 305-320.

Daisy, B.H., Strobel, G.A., Castillo, U., Ezra, D., Sears, J., Weaver, D.K., and Runyon, J.B. 2002. Naphthalene, an insect repellent, is produced by Muscodor vitigenus, a novel endophytic fungus. Microbiology 148: 3737-3741.

Elamo, P., Helander, M.L., Saloniemi, I., and Neuvonen, S. 1999. Birch family and environmental conditions affect endophytic fungi in leaves. Oecologia 118: 151-156.

Ezra, D., Hess, W.H., and Strobel, G.A. 2004. New endophytic isolates of Muscodor albus, a volatile-antibiotic-producing fungus. Microbiology 150: 4023-4031. 
Hall, T. A. 1999. BioEdit: a user-friendly biological sequence alignment editor and analysis program for Windows 95/98/NT. Nucl. Acids Symp. Ser. 41: 95-98.

Hata, K., Atari, R., and Sone, K. 2002. Isolation of endophytic fungi from leaves of Pasania edulis and their within-leaf distributions. Mycoscience 43: 369-373.

Helander, M.L., and Rantio-Lehtimäki, A. 1990. Effects of watering and simulated acid rain on quantity of phyllosphere fungi of birch leaves. Microb. Ecol. 19: 119-125.

Helander, M.L., Neuvonen, S., Sieber, T., and Petrini, O. 1993a. Simulated acid rain affects birch leaf endophyte populations. Microb. Ecol. 26: 227-234.

Helander, M.L., Ranta, H., and Neuvonen, S. 1993b. Responses of phyllosphere microfungi to simulated sulphuric and nitric acid deposition. Mycol. Res. 97: 533-537.

Hudson, H.J. 1968. The ecology of fungi on plant remains above the soil. New Phytol. 67: 837-874.

Kinkel, L.L., and Andrews, J.H. 1988. Disinfection of living leaves by hydrogen peroxide. Trans. Br. Mycol. Soc. 91: 523-528. birch. Insect herbivore relationships. Ecography 20: 116-122. 
1 Lappalainen, J.H., and Yli-Mattila, T. 1999. Genetic diversity in Finland of the birch endophyte Gnomonia setacea as determined by RAPD-PCR markers. Mycol. Res. 103: $328-332$.

Lappalainen, J.H., Koricheva, J., Helander, M.L., and Haukioja, E. 1999. Densities of endophytic fungi and performance of leafminers (Lepidoptera: Eriocraniidae) on birch along a pollution gradient. Environ Pollution 104: 99-105.

7 Lacey, L.A., and Neven, L.G. 2006. The potential of the fungus, Muscodor albus, as a microbial control agent of potato tuber moth (Lepidoptera: Gelechiidae) in stored potatoes. J. Invertebrate Pathol. 91: 195-198.

Miura, K., and Kudo, M. 1970. An agar-medium for aquatic hyphomycetes. Trans. Mycol. Soc. Japan 11: 116-118.

Okane, I., Nakagiri, A., and Ito, T. 1997. Preliminary study of endophytic fungi in evergreen plants from Ishigaki and Iriomote islands. IFO Res. Commun. 18: 45-51. Can. J. Bot. 76: 657-663.

Osono, T. 2002. Phyllosphere fungi on leaf litter of Fagus crenata: occurrence, colonization, and succession. Can. J. Bot. 80: 460-469. 
1 Osono, T. 2008. Endophytic and epiphytic phyllosphere fungi of Camellia japonica: seasonal and leaf-age-dependent variations. Mycologia 100: 387-391.

3 Osono, T. 2009. Ecological studies of endophytic and epiphytic phyllosphere fungi of trees in Japan. Nihon Kingaku Kaiho 50: 1-20 (in Japanese with English abstract).

5 Osono T. 2012. Endophytic fungal assemblages on leaves of 73 deciduous tree species in a cool temperate forest. Appl. For. Sci. 21: in press.

7 Osono, T., and Mori, A. 2003. Colonization of Japanese beech leaves by phyllosphere fungi. Mycoscience 44: 437-441.

9 Osono, T., and Mori, A. 2004. Distribution of phyllosphere fungi within the canopy of giant dogwood. Mycoscience 45: 161-168.

11 Osono, T., and Mori, A. 2005. Seasonal and leaf age-dependent changes in occurrence of phyllosphere fungi of giant dogwood. Mycoscience 46: 273-279.

Osono, T., and Takeda, H. 1999. A methodological survey on incubation of fungi on leaf litter of Fagus crenata. Appl. For. Sci. Kansai 8: 103-108 (in Japanese with English abstract). 
1 Osono, T., Ishii, Y., and Hirose, D. 2008. Fungal colonization and decomposition of

3 Osono, T., Ishii, Y., Takeda, H., Seramethakun, T., Khamyong, S., To-Anun, C., Hirose, D., Tokumasu, S., and Kakishima, M. 2009. Fungal succession and lignin decomposition on Shorea obtusa leaves in a tropical seasonal forest in northern Thailand. Fun. Div. 36: 101-119.

7 Pianka, E.R. 1973. The structure of lizard communities. Ann. Rev. Ecol. Syst. 4: 53-74.

8 SAS Institute. 2005. JMP Statistical Discovery Software (ver. 6.0). SAS Institute, Cary.

9 Sahashi, N., Miyasawa, Y., Kubono, T., and Ito, S. 2000. Colonization of beech leaves by two endophytic fungi in northern Japan. For. Pathol. 30: 77-86.

11 Saikkonen, K. 2007. Forest structure and fungal endophytes. Fun. Biol. Rev. 21: 67-74.

Saikkonen, K., Helander, M.L., and Rousi, M. 2003. Endophytic foliar fungi in Betula spp. and their F1 hybrids. For. Path. 33: 215-222.

Sieber, T.N. 2007. Endophytic fungi in forest trees: are they mutualists? Fun. Biol. Rev. 21: 75-89. 
1 Tamura, K., Peterson, D., Peterson, N., Stecher, G., Nei, M. and Kumar, S. 2011. MEGA5:

2 Bot. 51: 2275-2290. 
1 Figure legend

2

3 Fig. 1. Principal components of endophytic fungal assemblages (a) and component loadings

4 of major OTUs (b). Symbols are indicated with the combination of tree species and month;

5 for example, Bg-N indicates Betula grossa in November. Tree species are as in Table 1. Mu,

6 Muscodor sp. 11Bg52; Ne, Nemania sp. 8Cs51; Gn, Gnomonia sp. 11Af11; Ga, Glomerella

7 acutata; Ap, Apiosporopsis sp. 11Af21; As, Asteroma sp. 8Ah91; Cc, Cladosporium

8 cladosporioides; Kh, Khuskia sp. 11Bg11; Ni, Nigrospora sp. 11Bg31; My, Mycosphaerella

$9 \quad$ sp. 8Ah31; Pe, Pestalotiopsis sp. 8Ch61. 
Fig . 1
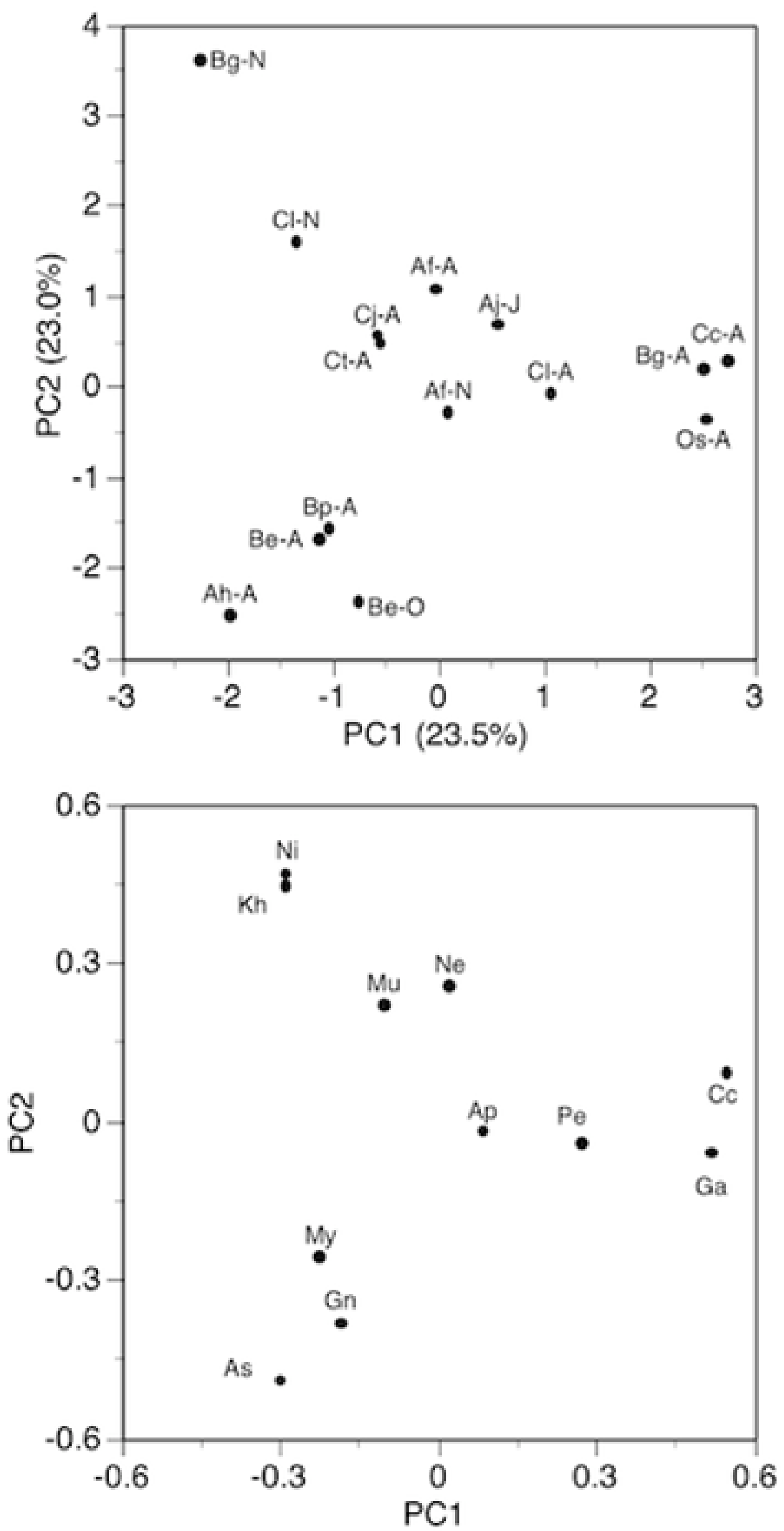
1 Table 1. Tree species, month of collection, and number of isolates and operational

2 taxonomic units (OTU) of endophytic fungi.

\begin{tabular}{|c|c|c|c|c|c|}
\hline Tree species & Abbr. & $\begin{array}{l}\text { Month } \\
\text { in } 2008\end{array}$ & $\begin{array}{l}\text { Number of } \\
\text { leaves } \\
\text { examined }\end{array}$ & $\begin{array}{l}\text { Number } \\
\text { of isolates }\end{array}$ & $\begin{array}{l}\text { Number } \\
\text { of OTU }\end{array}$ \\
\hline \multicolumn{6}{|l|}{ Subalpine forest } \\
\hline Alnus hirsuta var. sibirica & $\mathrm{Ah}$ & Aug & 10 & 12 & 7 \\
\hline \multirow[t]{3}{*}{ Betula ermanii } & $\mathrm{Be}$ & Jun & 10 & 0 & 0 \\
\hline & & Aug & 10 & 10 & 5 \\
\hline & & Oct & 10 & 12 & 4 \\
\hline Betula platyphylla var. japonica & Bp & Aug & 10 & 11 & 5 \\
\hline \multicolumn{6}{|l|}{ Cool temperate forest } \\
\hline \multirow[t]{3}{*}{ Alnus fima } & Af & May & 10 & 2 & 1 \\
\hline & & Aug & 10 & 14 & 9 \\
\hline & & Nov & 10 & 11 & 3 \\
\hline \multirow[t]{3}{*}{ Betula grossa } & $\mathrm{Bg}$ & May & 10 & 4 & 3 \\
\hline & & Aug & 10 & 12 & 6 \\
\hline & & Nov & 10 & 17 & 9 \\
\hline Corylus sieboldiana & Os & Aug & 10 & 13 & 6 \\
\hline \multirow[t]{3}{*}{ Carpinus laxiflora } & $\mathrm{Cl}$ & May & 10 & 2 & 2 \\
\hline & & Aug & 10 & 6 & 5 \\
\hline & & Nov & 10 & 16 & 13 \\
\hline C. tschonoskii & $\mathrm{Ct}$ & Aug & 10 & 8 & 2 \\
\hline C. japonica & $\mathrm{Cj}$ & Aug & 10 & 10 & 4 \\
\hline C. cordata & $\mathrm{Cc}$ & Aug & 10 & 13 & 7 \\
\hline \multicolumn{6}{|l|}{ Subtropical forest } \\
\hline Alnus japonica & $\mathrm{Aj}$ & Jul & 10 & 13 & 7 \\
\hline Total & & & 190 & 186 & \\
\hline
\end{tabular}


2 Table 2. Blast search result of 46 operational taxonomic units (OTU) of endophytic fungi isolated from leaves of Betulaceae in Japan.

\begin{tabular}{|c|c|c|c|c|c|}
\hline Blast search result & Accession No. & Score $(\%)$ & Number of isolates & OTU & Accession No. of OTU \\
\hline Muscodor fengyangensis & HМ034862 & 99 & 21 & Muscodor sp. 11Bg52 & AB669030 \\
\hline Fungal sp. mh337.6 & GU55255 & 98 & 20 & Nemania sp. 8Cs51 & AB669031 \\
\hline Gnomonia setacea & AF277135 & 98 & 17 & Gnomonia sp. 11Af11 & AB669032 \\
\hline Glomerella acutata & DQ286223 & 99 & 16 & Glomerella acutata & AB669033 \\
\hline Apiosporopsis carpinea & AF277130 & 98 & 14 & Apiosporopsis sp. 11Af21 & AB669034 \\
\hline Asteroma alneum & EU167609 & 98 & 8 & Asteroma sp. 8Ah91 & AB669035 \\
\hline Davidiella tassiana & AY251078 & 99 & 8 & Cladosporium cladosporioides & AB669036 \\
\hline Khuskia sp. & FJ890387 & 95 & 6 & Khuskia sp. 11Bg11 & AB669037 \\
\hline Nigrospora sp. & EU852533 & 99 & 6 & Nigrospora sp. 11Bg31 & AB669038 \\
\hline Mycosphaerella berberidis & EU167603 & 98 & 5 & Mycosphaerella sp. 8Ah31 & AB669039 \\
\hline Pestalotiopsis photiniae & DQ657877 & 98 & 5 & Pestalotiopsis sp. 8Ch61 & AB669040 \\
\hline Botryosphaeria dothidea & EU673243 & 98 & 4 & Botryosphaeria sp. 5Af11 & AB669041 \\
\hline Phomopsis sp. & EU219393 & 98 & 4 & Phomopsis sp. 8Af32 & AB669042 \\
\hline Biscogniauxia sp. & DQ840054 & 97 & 3 & Biscogniauxia sp. 8Bg12 & AB669043 \\
\hline Xylariaceae sp. & DQ674832 & 98 & 3 & Annulohypoxylon sp. 8Af31 & AB669044 \\
\hline Annulohypoxylon moriforme & DQ840058 & 99 & 3 & Annulohypoxylon sp. 8Bp31 & AB669045 \\
\hline Glomerella cingulata & DQ286193 & 99 & 3 & Glomerella cingulata & AB669046 \\
\hline Daldinia childiae & EF562505 & 95 & 3 & Daldinia sp. 11Bg22 & AB669047 \\
\hline Rosellinia corticium & DQ840078 & 98 & 3 & Rosellinia sp. 8Af62 & AB669048 \\
\hline Venturia tremulae var. tremulae & EU035475 & 99 & 3 & Venturia sp. 8Be61 & AB669049 \\
\hline Fungal endophyte isolate 9202 & EF420079 & 95 & 2 & Xylaria sp. 11Bg53 & AB669050 \\
\hline Gnomonia rostellata & $\mathrm{EF} 212860$ & 97 & 2 & Gnomonia sp. 7Aj71 & AB669051 \\
\hline Pestalotiopsis sp. AJH26 & EU605882 & 94 & 2 & Pestalotiopsis sp. 11Cl72 & AB669052 \\
\hline Thuemenella cubispora & EF562509 & 95 & 2 & Thuemenella sp. 8Af22 & AB669053 \\
\hline
\end{tabular}




\begin{tabular}{|c|c|c|c|c|c|}
\hline Chlorencoelia sp. & AY789351 & 93 & 2 & Chlorencoelia sp. 8Bg11 & AB669054 \\
\hline Arthrinium phaeospermum & AY083832 & 98 & 1 & Arthrinium phaeospermum & AB669055 \\
\hline Botryosphaeria parva & AY928046 & 99 & 1 & Botryosphaeria sp. 8Af12 & AB669056 \\
\hline Chaetomium bostrychodes & AF286395 & 96 & 1 & Chaetomium sp. 11C121 & AB669057 \\
\hline Coniochaeta velutina & EU999180 & 96 & 1 & Coniochaeta sp. 11Af32 & AB669058 \\
\hline Diaporthe eres & AF362565 & 99 & 1 & Diaporthe sp. 8Cs61 & AB669059 \\
\hline Diaporthe acaciigena & DQ377874 & 91 & 1 & Diaporthe sp. $11 \mathrm{Cl} 22$ & AB669060 \\
\hline Didymella fabae & FJ755246 & 93 & 1 & Didymella fabae & AB669061 \\
\hline Uncultured Pleosporales & EU490012 & 91 & 1 & Dothideomycetes sp. 11Bg71 & AB669062 \\
\hline Allantophoma endogenospora & EU754126 & 94 & 1 & Gnomonia sp. 11Bg1 & AB669063 \\
\hline Penicillium verruculosum & AF510496 & 99 & 1 & Penicillium verruculosum & AB669064 \\
\hline Pestalotiopsis aff. palmarum & FJ890415 & 97 & 1 & Pestalotiopsis sp. 11Bg91 & AB669065 \\
\hline Uncultured Leotiomycetes & JF449482 & 97 & 1 & Phialophora sp. 5Bg41 & AB669066 \\
\hline Phomopsis sp. & AB107264 & 90 & 1 & Phomopsis sp. 11CL13 & AB669067 \\
\hline Uncultured soil fungus & EU692696 & 96 & 1 & fungal sp. 8Ah82 & AB669068 \\
\hline Pseudoplectania nigrella & AY945852 & 91 & 1 & fungal sp. $5 \mathrm{Cl} 21$ & AB669069 \\
\hline Anthostomella leucospermi & EU552100 & 95 & 1 & Xylaria sp. 8 Cs 12 & AB669070 \\
\hline Biscogniauxia nummularia & GQ428318 & 96 & 1 & fungal sp. 8Ci42 & AB669071 \\
\hline Cryptodiaporthe aesculi & DQ836905 & 98 & 1 & Cryptodiaporthe sp. 8Ah92 & AB669072 \\
\hline Harknessia gibbosa & EF110615 & 93 & 1 & Harknessia sp. 11Af41 & AB669073 \\
\hline Trimmatostroma salicis & EU019300 & 96 & 1 & Trimmatostroma sp. $8 \mathrm{Cl} 62$ & AB669074 \\
\hline Coniothyrium nitidae & EU552112 & 96 & 1 & Coniothyrium sp. 8C193 & AB669075 \\
\hline
\end{tabular}


1 Table 3. Frequency of occurrence (\%) of major five OTUs of endophytic fungi on leaves of Betulaceae in Japan. Tree species are as in Table 1.

\begin{tabular}{|c|c|c|c|c|c|c|}
\hline Tree species & Month in 2008 & $\begin{array}{l}\text { Muscodor sp. } \\
11 \mathrm{Bg} 52\end{array}$ & $\begin{array}{l}\text { Nemania sp. } \\
8 \mathrm{Cs} 51\end{array}$ & $\begin{array}{l}\text { Gnomonia sp. } \\
\text { 11Af11 }\end{array}$ & Glomerella acutata & $\begin{array}{l}\text { Apiosporopsis sp. } \\
\text { 11Af21 }\end{array}$ \\
\hline \multicolumn{7}{|c|}{ Subalpine forest } \\
\hline $\mathrm{Ah}$ & Aug & 0 & 10 & 0 & 0 & 0 \\
\hline \multirow[t]{3}{*}{$\mathrm{Be}$} & Jun & 0 & 0 & 0 & 0 & 0 \\
\hline & Aug & 0 & 10 & 40 & 0 & 0 \\
\hline & Oct & 0 & 0 & 70 & 20 & 0 \\
\hline $\mathrm{Bp}$ & Aug & 10 & 0 & 60 & 0 & 0 \\
\hline \multicolumn{7}{|c|}{ Cool temperate forest } \\
\hline \multirow[t]{3}{*}{ Af } & May & 0 & 0 & 0 & 0 & 0 \\
\hline & Aug & 50 & 10 & 0 & 0 & 0 \\
\hline & Nov & 0 & 0 & 0 & 0 & 90 \\
\hline \multirow[t]{3}{*}{$\mathrm{Bg}$} & May & 0 & 10 & 0 & 0 & 0 \\
\hline & Aug & 0 & 20 & 0 & 40 & 10 \\
\hline & Nov & 20 & 30 & 0 & 0 & 0 \\
\hline Os & Aug & 0 & 0 & 0 & 30 & 20 \\
\hline \multirow[t]{3}{*}{$\mathrm{Cl}$} & May & 0 & 0 & 0 & 0 & 10 \\
\hline & Aug & 10 & 0 & 0 & 20 & 0 \\
\hline & Nov & 0 & 0 & 0 & 0 & 10 \\
\hline $\mathrm{Ct}$ & Aug & 70 & 0 & 0 & 0 & 0 \\
\hline $\mathrm{Cj}$ & Aug & 40 & 40 & 0 & 0 & 0 \\
\hline $\mathrm{Cc}$ & Aug & 10 & 20 & 0 & 50 & 0 \\
\hline \multicolumn{7}{|c|}{ Subtropical forest } \\
\hline $\mathrm{Aj}$ & Jul & 0 & 50 & 0 & 0 & 0 \\
\hline
\end{tabular}


Table 4. Pianka's similarity index for endophytic fungal assemblages on leaves among subalpine, cool temperate, and subtropical tree species. Tree species are as in Table 1. na data not available.

\begin{tabular}{lllccc}
\hline Tree genus & Tree species & Month & $\begin{array}{l}\text { Subalpine vs } \\
\text { cool temperate }\end{array}$ & $\begin{array}{c}\text { Subalpine vs } \\
\text { subtropic }\end{array}$ & $\begin{array}{c}\text { Cool temperate } \\
\text { vs subtropic }\end{array}$ \\
\hline Alnus & Ah, Af, Aj & Jul-Aug & 0.03 & 0.15 & 0.30 \\
Betula & Be, Bg & Aug & 0.07 & na & na \\
& & Oct-Nov & 0.02 & na & na \\
& Bp, Bg & Aug & 0.00 & na & na \\
\hline
\end{tabular}


5 Table 5. Pianka's similarity index for endophytic fungal assemblages on leaves among tree

6 species. Tree species are as in Table 1.

(1) Subalpine forest, August

\begin{tabular}{lccc}
\hline & Ah & Be & Bp \\
\hline $\mathrm{Ah}$ & & 0.32 & 0.08 \\
$\mathrm{Be}$ & & 0.84 \\
$\mathrm{Bp}$ & & & \\
\hline
\end{tabular}

(2) Cool temperate forest, August

\begin{tabular}{|c|c|c|c|c|c|c|c|}
\hline & Af & $\mathrm{Ct}$ & $\mathrm{Cj}$ & $\mathrm{Bg}$ & $\mathrm{Cl}$ & $\mathrm{Cc}$ & Os \\
\hline Af & & 0.82 & 0.69 & 0.12 & 0.35 & 0.25 & 0.05 \\
\hline $\mathrm{Ct}$ & & & 0.68 & 0.00 & 0.35 & 0.16 & 0.00 \\
\hline $\mathrm{Cj}$ & & & & 0.25 & 0.24 & 0.34 & 0.00 \\
\hline $\mathrm{Bg}$ & & & & & 0.65 & 0.84 & 0.46 \\
\hline $\mathrm{Cl}$ & & & & & & 0.76 & 0.39 \\
\hline $\mathrm{Cc}$ & & & & & & & 0.46 \\
\hline Os & & & & & & & \\
\hline
\end{tabular}

(3) Cool temperate forest, November

\begin{tabular}{lccc} 
& Af & $\mathrm{Bg}$ & $\mathrm{Cl}$ \\
\hline $\mathrm{Af}$ & & 0.00 & 0.21 \\
$\mathrm{Bg}$ & & & 0.52 \\
$\mathrm{Cl}$ & & & \\
\hline
\end{tabular}


6 Table 6. Pianka's similarity index for endophytic fungal assemblages on leaves among

7 seasons. Tree species are as in Table 1. na data not available.

\begin{tabular}{llccc}
\hline Forest type & Tree species & May-Jun vs Aug & May-Jun vs Oct & Aug vs Oct-Nov \\
\hline Subalpine & Be & na & na & 0.82 \\
Cool temperate & Af & 0.00 & 0.00 & 0.00 \\
& Bg & 0.15 & 0.19 & 0.17 \\
& Cl & 0.00 & 0.15 & 0.00 \\
\hline
\end{tabular}

8 